\title{
Can persistent hiccups be a progression marker in COVID-19?
}

\author{
๑Handan Alay ${ }^{1}$, ®Nazım Doğan ${ }^{2}$, ๑Zülal Özkurt ${ }^{1}$, ๑Nuray Bilge ${ }^{3}$, ๑Fatma Kesmez Can ${ }^{1}$, \\ (1) Ömer Araz ${ }^{4}$ \\ ${ }^{1}$ Ataturk University, School of Medicine, Department of Infectious Disease and Clinical Microbiology, Erzurum, Turkey \\ ${ }^{2}$ Ataturk University, School of Medicine, Department of Anesthesiology and Reanimation, Erzurum, Turkey \\ ${ }^{3}$ Ataturk University, School of Medicine, Department of Neurology, Erzurum, Turkey \\ ${ }^{4}$ Ataturk University, School of Medicine, Department of Pulmonary Disease, Erzurum, Turkey
}

Cite this article as: Alay H, Doğan N, Özkurt Z, Bilge N, Kesmez Can F, Araz Ö. Can persistent hiccups be a progression marker in COVID-19? J Health Sci Med 2021; 4(2): 240-242.

\begin{abstract}
Hiccup is a reflex action that may rarely be intractable. A 55-year-old man diagnosed with COVID-19 was hospitalized to our clinic with body temperature elevation, weakness, and headache persisting for the previous three days. Persistent hiccups were present during follow-up, and progression was observed at pulmonary tomography with an increase in the numbers and dimensions of focal ground glass areas. Lymphocyte count was $920 / \mu \mathrm{L}$, platelet count $138 \times 10^{3} / \mu \mathrm{L}$, sedimentation rate $6 \mathrm{~mm} / \mathrm{h}$, ferritin $1256 \mathrm{ng} / \mathrm{mL}$, C-reactive protein $16.8 \mathrm{mg} / \mathrm{L}$, aspartate aminotransferase $43 \mathrm{U} / \mathrm{L}$, alanine aminotransferase $67 \mathrm{U} / \mathrm{L}$, and lactate dehydrogenase 326 U/L. Other potential causes of persistent hiccups were excluded. COVID-19 immune plasma and remdesivir therapy were initiated. The hiccups resolved two days after treatment, and the patient was discharged on the $11^{\text {th }}$ day of follow-up. Persistent hiccups should be remembered among the symptoms that may appear during the clinical progression of COVID-19.
\end{abstract}

Keywords: Persistent hiccups, progression, COVID-19

\section{INTRODUCTION}

Unidentified cases of viral pneumonia were detected in the city of Wuhan in the Chinese province of Hubei in December 2019. These spread rapidly, and growing numbers of cases also began being seen in other countries. The World Health Organization announced the existence of COVID-19 disease, meaning coronavirus disease 2019, in February 2020 (1). The virus uses angiotensinconverting enzyme type 2 (ACE-2) receptors to bind to cells (2). ACE-2 receptors are found in endothelial cells and in several organs, including nervous system tissue (3).

The most frequently seen symptoms include fever, cough, fatigue, phlegm, shortness of breath, sore throat, and headache. Gastrointestinal symptoms such as diarrhea and vomiting may also be seen, although less frequently (4). Anosmia has been widely reported as an early onset symptom (5). Neurological diseases such as cerebral hemorrhage and cerebral infarction have also been reported in addition to nonspecific symptoms such as headache, lethargy, and gait disturbance $(6,7)$.

Hiccups are a widespread and transiententity that can affect almost all individuals during their lives. They results from involuntary contraction of the diaphragm and intercostal muscles. Hiccups exceeding $48 \mathrm{~h}$ in duration are rare and can derive from severe diseases (8). Etiological factors include cerebrovascular disease, coronary artery disease, diaphragmatic hernia, metabolic disease, duodenal ulcer, and psychogenic and other causes (9). Here, we describe a case report of a male patient with a rare association of COVID-19 and persistent hiccups.

\section{CASE}

A 55-year-old man receiving favipiravir therapy due to diagnosis of COVID-19 five days previously was hospitalized in our clinic due to fever, weakness, and headache persisting for three days despite treatment. The patient had no history of chronic disease, malignancy, or smoking. No nasal discharge, nasal obstruction, sore throat, or shortness of breath were present at system examination. The patient was a health worker, but had no history of unprotected high-risk contact or travel. Vital signs were body temperature $38.4^{\circ} \mathrm{C}$, heart rate 78 beats/ min, blood pressure $120 / 80 \mathrm{mmHg}$, respiratory rate $25 /$ min, and oxygen saturation $\left(\mathrm{SO}_{2}\right)$ in room air 95. All systems were normal at physical examination. Pulmonary tomography findings were present in the form of ground glass opacities with irregular borders in the lower lobes 
of both lungs (Figure 1). White blood cell (WBC) count was $4.88 \times 10^{3} / \mu \mathrm{L}$, lymphocyte count $1010 / \mu \mathrm{L}$, platelet count $133 \times 10^{3} / \mu \mathrm{L}$, sedimentation rate $5 \mathrm{~mm} / \mathrm{h}$, D-dimer $243 \mathrm{ng} / \mathrm{mL}$, ferritin $529 \mathrm{ng} / \mathrm{mL}$, procalcitonin $0.09 \mathrm{ng} /$ $\mathrm{ml}$, c-reactive protein (CRP) $3.17 \mathrm{mg} / \mathrm{L}$, aspartate amino transferase (AST) $19 \mathrm{U} / \mathrm{L}$, alanine aminotransferase (ALT) $34 \mathrm{U} / \mathrm{L}$, and lactate dehydrogenase (LDH) 180 U/L. Metilprednizolon $60 \mathrm{mg} /$ day, levofloxacin $750 \mathrm{mg} /$ day, and enoxaparin sodium $0.6 \mathrm{ml} /$ day were added to the existing favipavir therapy. Persistent hiccups occurred together with persisting and refractory fever on the third day of hospitalization. The patient's $\mathrm{SO}_{2}$ in room air was 89 , and increases in the numbers and dimensions of focal ground glass areas were observed at control pulmonary tomography (Figure 2). Laboratory parameters were WBC $7.78 \times 10^{3} / \mu \mathrm{L}$, lymphocyte count $920 / \mu \mathrm{L}$, platelet count $138 \times 10^{3} / \mu \mathrm{L}$, sedimentation rate $6 \mathrm{~mm} / \mathrm{h}$, ferritin $1256 \mathrm{ng} /$ $\mathrm{mL}, \mathrm{CRP} 16.8 \mathrm{mg} / \mathrm{L}$, AST $43 \mathrm{U} / \mathrm{L}$, ALT $67 \mathrm{U} / \mathrm{L}$, and LDH $326 \mathrm{U} / \mathrm{L}$. The patient's fever persisted and no improvement was observed in symptoms, and convalescent plasma therapy was administered. Favipavir was stopped, and remdesivir was initiated at $1 \times 100 \mathrm{mg} /$ day (five days) after $1 \times 200 \mathrm{mg} 1 \times 1$. On the fourth day of follow-up, the patient's body temperature was $38.3^{\circ} \mathrm{C}$. Oxygen was given at $4 \mathrm{lt} / \mathrm{min}$ through a nasal cannula, and the patient's $\mathrm{SO}_{2}$ was 92 . Our patient was evaluated by the neurology clinic. Neurological examination and cranial magnetic resonance imaging (MRI) were normal. The hiccups persisted, and a singular intramuscular $25 \mathrm{mg}$ dose of chlorpromazine was administered. Other system evaluations potentially related to persistent hiccups were normal. The patient's body temperature returned to normal on the sixth day of follow-up, the hiccups resolved, and he was discharged in a healthy condition on the $11^{\text {th }}$ day.

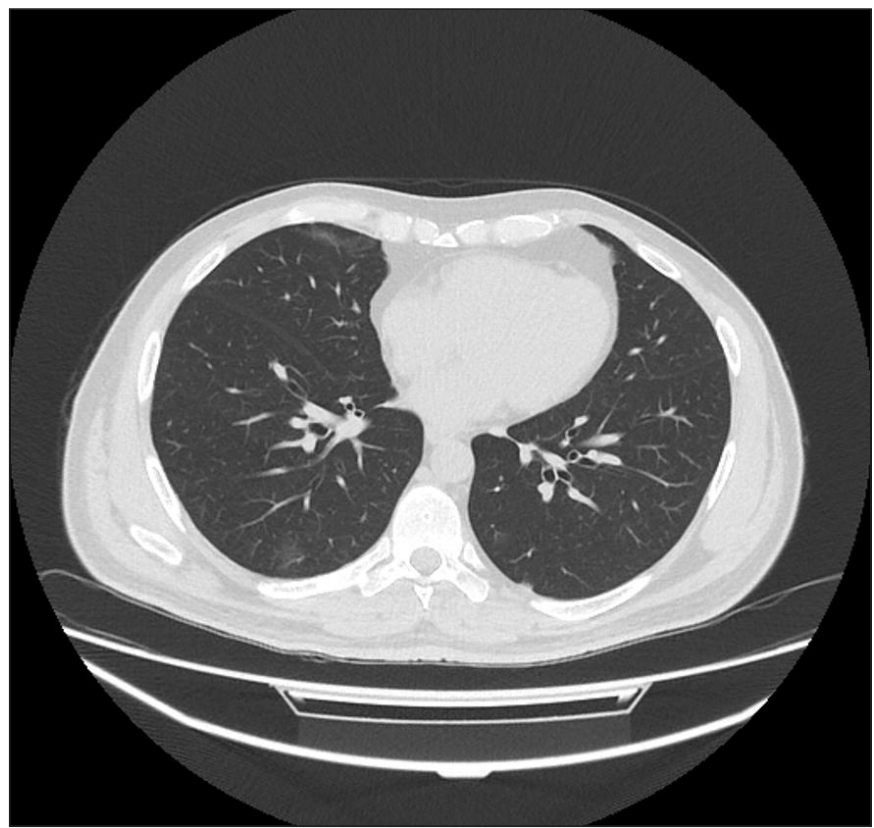

Figure 1. Ground glass opacities with indefinite borders located peripherally in the lower lobes of both lungs

\section{DISCUSSION}

Spike proteins of severe acute respiratory syndrome virus-2 (SARS-CoV-2), which causes coronavirus disease, use ACE-2 receptors to bind to cells. ACE2 receptors are also expressed in the central nervous system $(2,3)$. ACE-2 receptors are also expressed in the central nervous system $(2,3)$. In the literature, headache, dizziness, impaired consciousness, epilepsy, ataxia, acute disseminated encephalomyelitis and viral encephalitis are among the neurological symptoms of COVID-19 $(10,11)$. Headache is the most common central nervous system symptom with a prevalence between 6.5 and $23 \%$ (12). In our case, headache was among the complaints at the time of admission to hospital.

New information regarding the clinical characteristics of COVID-19 is constantly emerging. The present case, diagnosed with COVID-19 and with persistent hiccups, will add to the abnormal clinical characteristics of COVID-19. This is the first report of this clinical feature from Turkey, and the second in the literature. The previous, first case report concerned a patient presenting to the emergency department with persistent hiccups and diagnosed with COVID-19 at subsequent follow-up. Apart from persistent hiccups, the patient who does not have fever, nasal congestion, sore throat, chest pain or shortness of breath is reported to have no travel or patient contact (13). In our case, fever, headache and malaise were the initial symptoms and persistent hiccups developed during follow-up.

In the case report in which COVID-19 was reported as an atypical admission complaint, it was reported that the case had leukopenia, thrombocytopenia, hyponatremia

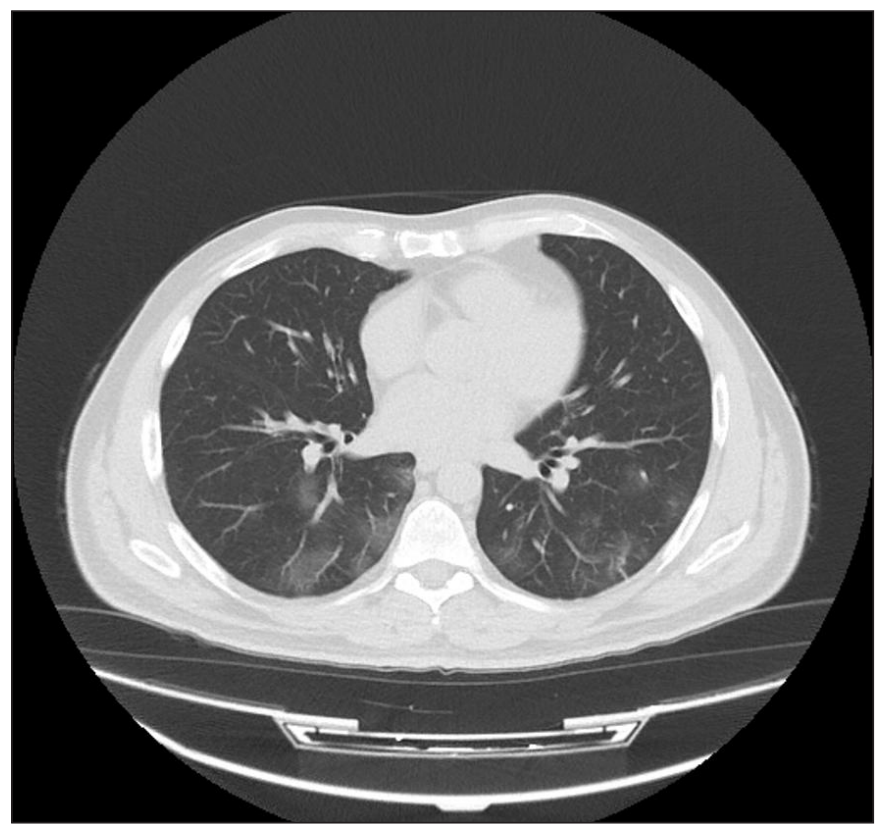

Figure 2. Increased numbers and dimensions of focal ground glass opacities in both lungs 
and hypochloremia, on the other hand, troponin, metabolic panel, lactate and urine tests were normal (13). Metabolic conditions that could cause persistent hiccups were normal in our patient.

Vagus or phrenic nerve irritations can cause persistent hiccups $(14,15)$. In the case with persistent hiccups and weight loss presented in the literature, contrast-enhanced chest CT performed to exclude a mediastinal mass and demonstrated small focal ground glass opacities scattered in the lungs and regional peripheral ground glass opacities of the upper lobes (13). In our case, which we followed up with the diagnosis of COVID-19, we saw that there was an increase in the numbers and dimensions of focal ground glass areas on contrast chest CT, which was taken with suspicion of a mass that could compress the vagus or phrenic nerve. No mediastinal pathology or diaphragmatic hernia was observed.

Vascular or infectious conditions of the central nervous system are included in the etiology of persistent hiccups $(16,17)$. Neurological examination and cranial MRI of our patient were normal. Even if no specific cause is found, detailed history must be taken and physical examination and diagnostic tests must be performed to identify the underlying cause and provide appropriate treatment. Apart from COVID-19, no other disease that could cause persistent hiccups was detected in our patient.

It is important to treat the underlying cause in patients with persistent hiccups. The present case report emphasized that clinical persistent hiccups may emerge in the progression stage of COVID-19. Atypical symptoms such as persistent hiccups in patients with no clinical and laboratory improvement should suggest the presence of progression, and treatment should be revised accordingly.

\section{ETHICAL DECLARATIONS}

Informed Consent: Written informed consent was obtained from all participants who participated in this study

Referee Evaluation Process: Externally peer-reviewed.

Conflict of Interest Statement: The authors have no conflicts of interest to declare.

Financial Disclosure: The authors declared that this study has received no financial support.

Author Contributions: All of the authors declare that they have all participated in the design, execution, and analysis of the paper, and that they have approved the final version.

\section{REFERENCES}

1. World Health Organization. Director-General's remarks at the media briefing on 2019-nCoV on 11 February 2020. http://www. who.int/dg/speeches/detail/who-director-general-s-remarksat-the-media-briefing-on-2019-ncov-on-11-february-2020 (Accessed on October 12, 2020).

2. Lu R, Zhao X, Li J, et al. Genomic characterisation and epidemiology of 2019 novel coronavirus: implications for virus origins and receptor binding. Lancet 2020; 395: 565-74.

3. Hamming I, Timens W, Bulthuis ML, Lely AT, Navis G, van Goor $\mathrm{H}$. Tissue distribution of ACE2 protein, the functional receptor for SARS coronavirus. A first step in understanding SARS pathogenesis. J Pathol 2004; 203: 631-7.

4. Guan WJ, Ni ZY, Hu Y, et al. Clinical characteristics of coronavirus disease 2019 in China. N Engl J Med 2020. doi:10.1056/ NEJMoa2002032.

5. Hopkins C, Kumar N. Loss of sense of smell as a marker of COVID-19 infection. ENTUK (cited 2020 November 12); Available from: https://www.entuk.org/sites/default/files/files/ Loss $\% 20$ of $\% 20$ sense $\% 20$ of $\% 20$ smell $\% 20$ as $\% 20$ marker\%20of $\% 20$ COVID.pdf

6. Mao L, Jin $\mathrm{H}$, Wang $\mathrm{M}$, et al. Neurologic manifestations of hospitalized patients with Coronavirus disease 2019 in Wuhan, China. JAMA Neurol 2020; 77: 683-90.

7. Alay H, Gözgeç E. Cerebral infarction in an elderly patient with coronavirus disease. Rev Soc Bras Med 2020; 53: e20200307.

8. Smith HS, Busracamwongs A. Management of hiccups in the palliative care population. Am J Hosp Palliat Care 2003; 20: 149.

9. Souadjian JV, Cain JC. Intractable hiccup. Etiologic factors in 220 cases. Postgrad Med 1968; 43: 72.

10. Wu Y, Xu X, Chen Z, et al. Nervous system involvement after infection with COVID-19 and other coronaviruses. Brain Behav Immun 2020. doi: 10.1016/j. bbi.2020.03.031.

11. Azhideh A. COVID-19 Neurological Manifestations. Int Clin Neurosci J 2020; 7: 54. doi: 10.34172/icnj.2020.01.

12. Rodriguez-Morales AJ, Cardona-Ospina JA, Gutiérrez-Ocampo E, et al. Clinical, laboratory and imaging features of COVID-19: A systematic review and meta-analysis. Travel Med Infect Dis 2020; 34: 101623. doi:10.1016/j.tmaid.2020.101623

13. Prince G, Sergel M. Persistent hiccups as an atypical presenting complaint of COVID-19. Am J Emerg Med. 2020; 38: 1546.e51546.e6.

14. Payne BR, Tiel RL, Payne MS, Fisch B. Vagus nerve stimulation for chronic intractable hiccups. Case report. J Neurosurg 2005; 102: 935

15. Renes SH, van Geffen GJ, Rettig HC, et al. Ultrasound-guided continuous phrenic nerve block for persistent hiccups. Reg Anesth Pain Med 2010; 35: 455.

16. Park MH, Kim BJ, Koh SB, et al. Lesional location of lateral medullary infarction presenting hiccups (singultus). J Neurol Neurosurg Psychiatry 2005; 76: 95.

17. Nagayama $\mathrm{T}$, Kaji $\mathrm{M}$, Hirano $\mathrm{H}$, et al. Intractable hiccups as a presenting symptom of cerebellar hemangioblastoma. Case report. J Neurosurg 2004; 100: 1107. 